\title{
Determination of Slope of Enugu for Erosion Models
}

\author{
G.I. Okolotu, P.C. Eze, C.N. Eze. \\ Department of Agricultural and Bioresource Engineering, Enugu State University of Science and Technology, P.M.B. 01660, \\ Enugu, Nigeria.
}

\begin{abstract}
Slope in soil erosion models (soil loss equations) refer to slope components known as the LS factor. Generating the LS values poses the largest problem in using the Universal Soil Loss Equation (USLE). This work gives the practical solution to slope determination using two methods; the direct field measurement and the topomap techniques. From direct field measurement technique, slope was ascertained by excavation of the study area and measurement of the selected vertical distance (rise) over a selected horizontal distance (run), which was used for the determination of the slope length and gradient (angle) using the general slope equations. Using the topomap method, point $A$ and $B$ were identified on the map sheet, the elevations of point $A$ and $B$ were obtained from the contour lines while the distance of the two points were obtained from the map using a meter rule and the map scale. The values of their elevations (rise) over their distances (run) were used to compute slope length which was useful in obtaining slope angle. Either way, the values of $L$ and $S$ were multiplied together to generate a single value known as the LS factor which is applicable in the Universal soil loss equation and other erosion models to be developed in the area in future years. These models can be used to calculate and predict soil erosion occurrence in the study area; Enugu State of Nigeria. Slope management techniques to minimize erosion were also prescribed as a prevention strategy rather than remediation of eroded soil.
\end{abstract}

Keywords - soil erosion, slope, gradient, universal soil loss, Enugu State.

\section{INTRODUCTION}

A slope is the measure of steepness or degree of inclination of a feature relative to the horizontal plane. It has been demonstrated that increase in slope length and slope steepness can produce higher overland flow velocities and correspondingly higher erosion [5]. While slope measures the degree of inclination, it also exist as a declination which it also a measure of significant. Climbing from the foot of a hill toward the top is a rising slope and vice versa (towards downhill) is a falling slope. These can be seen by the www.ijeab.com directions of the two arrows in fig. 1. An escarpment is a steep slope or long cliff that forms as an effect of faulting or erosion thereby separating two relatively level areas of differing elevations. Enugu's hill at the extreme is about 1,000 meters $(3,300 \mathrm{ft})$ in elevation. From the satellite map below, (fig. 2) Enugu escarpment can be seen on the left where it has a lighter colour.

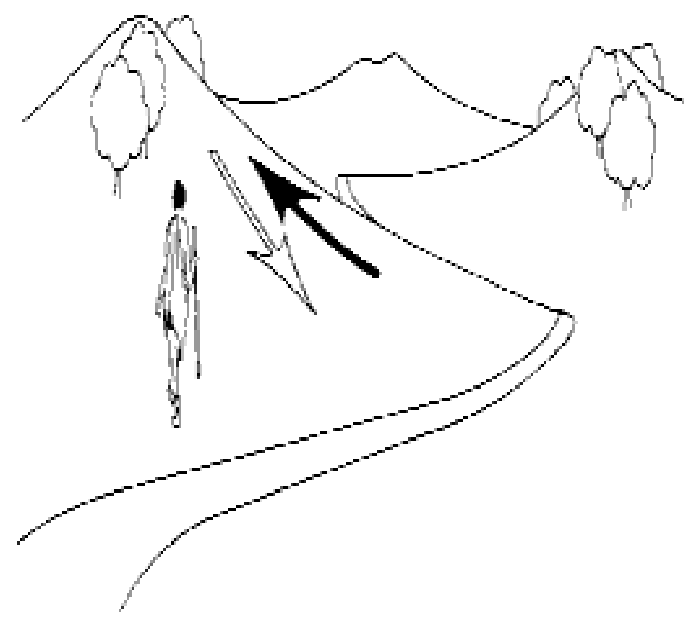

Fig. 1: A rising and a falling slope (FAO, 1995). (NASA, 2007).

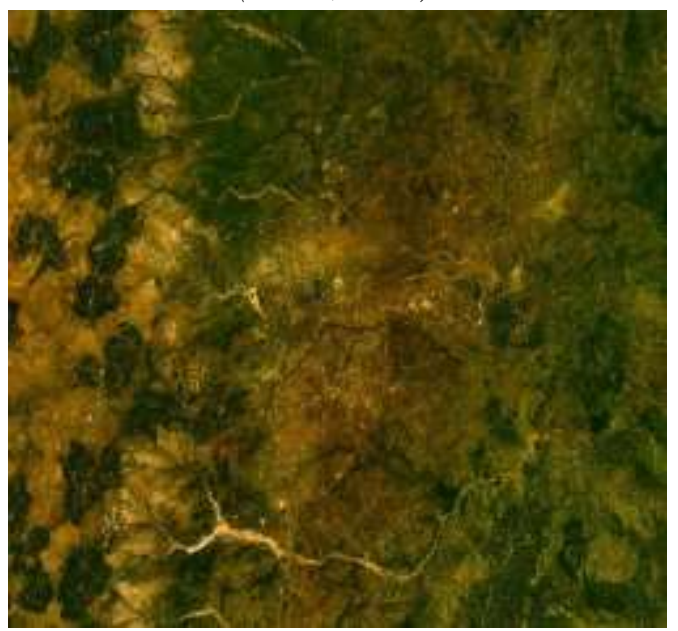

Fig. 2: Satellite map of Enugu, Nigeria (NASA, 2007). 
It is necessary to understand the various shapes of slope because slope shape determines whether water is dispersed or concentrated. Convex slope, flat or straight slope and concave slope are the three main types of slope shapes. Convex slopes roll from less steep to steeper terrain. Flat slopes otherwise known as straight or parallel slopes areas are never strictly horizontal, there are gentle slopes in a seemingly flat area, they are often hardly noticeable to the naked eye, and they demand an accurate survey of land to be identified. Concave slopes go from steeper to gentler terrain with movement down slope. Slope plays an important role in soil erosion models like; USLE, RUSLE, AGNPS, ANSWERS, WEEPS, e.t.c. It is represented as LS factor which include the slope length and slope angle. The $\mathrm{L}$ and $\mathrm{S}$ factor are commonly combined as LS and are referred as the slope factor [6]; [9]. This slope factor can be obtained either by field measurement or by using the topomap method. Therefore, the objective of this research is to determine the slope of Enugu for erosion models.

\section{THE STUDY AREA:}

The study area; Enugu State of Nigeria, West Africa, derived its name "Enugu" from the two Igbo words "enu" and "ugwu" meaning hill top prior to its hilly geography. It lies approximately within latitude $6^{\circ} 31^{\prime \prime} \mathrm{N}$ and $7^{\circ} 16^{\prime \prime} \mathrm{N}$ and longitude $7^{\circ} 20^{\prime}$ 'E and $7^{\circ} 41^{\prime \prime} \mathrm{E}$. Its capital city, Enugu, lies approximately within latitude $6^{\circ} 20^{\prime \prime} \mathrm{N}$ and $7^{\circ} 30^{\prime} \mathrm{N}$ and longitude $7^{\circ} 20^{\prime \prime} \mathrm{E}$ and $7^{\circ} 30^{\prime}$ 'E. Enugu is bounded by several other states; in the North by Benue and Kogi States, in the South by Abia and Imo States, while in the West and East by Anambra and Ebonyi States respectively. Minerals mined in Enugu State includes; coal, iron ore, fine clay, silica sand, lime stone, and marble [14]. The climate is tropical hinterland in nature and is comparatively congenial, characterized by high temperature, high humidity and substantial rainfall which is entirely seasoned, most of it falling between May and October [14]. These locations are described in the map below;

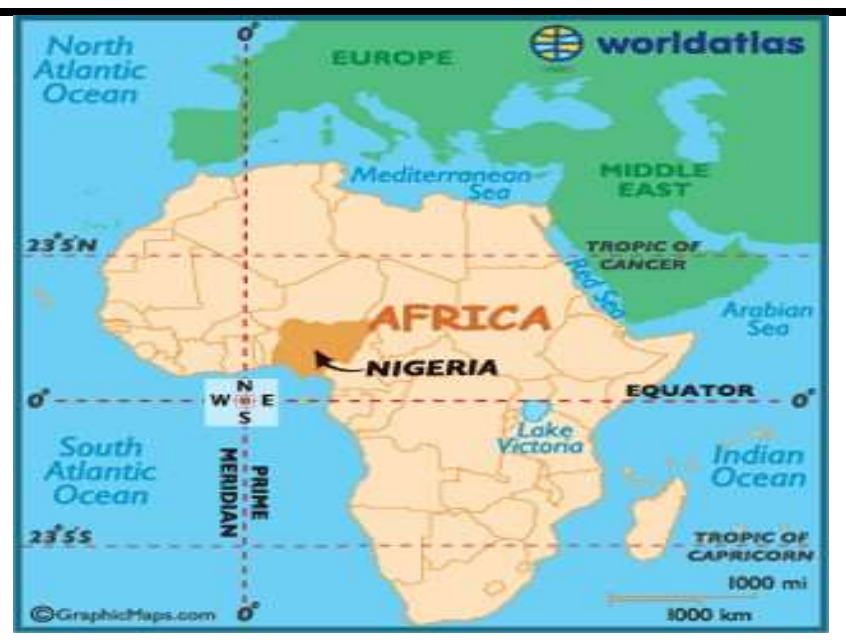

Fig. 3: Map of Nigeria with Enugu ) (Wikipedia, 2013, Atlas, 2016)

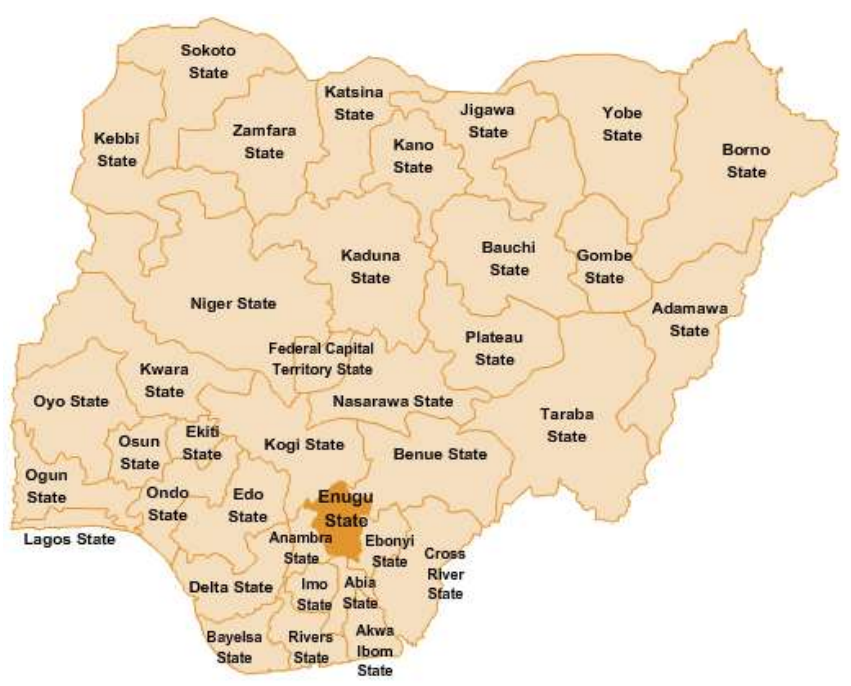

Fig. 4: Map of Africa with Nigeria (Wikipedia,2013, Atlas, 2016

\section{MATERIALS AND METHODS}

The major materials used in the field measurement techniques are; the excavator machine and the measuring tape. Excavator machine, this is a heavy duty equipment used in earthwork operations. $\mathrm{Cat}_{(\mathrm{R})} 336 \mathrm{EH}$ hydraulic excavator was used to dig through the soil to a desired length of cut (vertical distance of $7.2 \mathrm{~m}$ or 24 feet and horizontal distance of $29.1 \mathrm{~m}$ or $97 \mathrm{feet}$ ) so as to take the run and rise measurements. The machine has net flywheel Power of $286.0 \mathrm{hp}$, Engine model of $\mathrm{Cat}_{(\mathrm{R})} \mathrm{C} 9.3$ (ATAAC), Bores at $0.1151 \mathrm{~m}$, Operating weight of $37194.58 \mathrm{~kg}$ (minimum operating weight of $37013.14 \mathrm{~kg}$ and maximum operating weight of $37194.57 \mathrm{~kg}$ ), Maximum travel speed of $3.0 \mathrm{mph}$, Maximum drawback pull of $30081.79 \mathrm{~kg}$, Swing system maximum flow of $73.0 \mathrm{gal} / \mathrm{min}$, Heavy lift maximum pressure of 5366.0 psi, Fuel tank capacity of 
163.8 gal, Sound performance (Operating noise) of $71.0 \mathrm{~dB}$. This excavator machine is shown in figure 6 . The measuring tape is a measuring instrument used in taking reading in different units like inch, meter, and feet, convertible to other units of measurement. The Heng Feng ${ }_{\circledast}$, POWERLOCK $19 \mathrm{~mm}$ measuring tape was used to measure the topographic run and rise distances on the field $(26.50 \mathrm{~m}$ and $5.55 \mathrm{~m}$, horizontally and vertically respectively) necessary for slope determination. This measuring tape is shown in figure 7. Also, the major materials used in topomap technique are; the topomap and the meter rule. The topomap (topographic map with contour readings) was used to obtain the elevation and distance of Enugu State. An example of this map is shown in figure 9. The second apparatus used is the Meter rule, this is a calibrated plastic, glass, wood, e.t.c., that measures readings as low as in centimeter $(\mathrm{cm})$, this was used to measure the distances on the topomap before converting the unit prior the map scale. The slope of a field is expressed as a ratio of its vertical distance (rise) or difference in height between two points in a field, divided by the horizontal distance (run). In Enugu metropolis, slope was calculated from direct field measurement by; excavation of the soil (vertical distance of $7.2 \mathrm{~m}$ or 24 feet and horizontal distance of $29.1 \mathrm{~m}$ or $97 \mathrm{feet}$ ), measurement of selected run and rise distances $(26.50 \mathrm{~m}$ horizontally and $5.55 \mathrm{~m}$ vertically), and determination of slope length, slope angle and LS factor using the following slope equation 1 ;

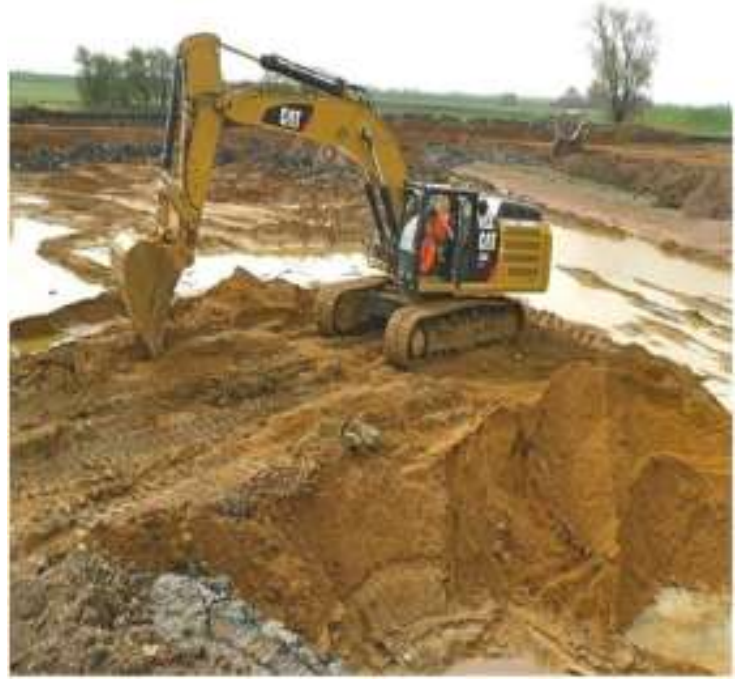

Fig. 5: Hydraulic Excavator.

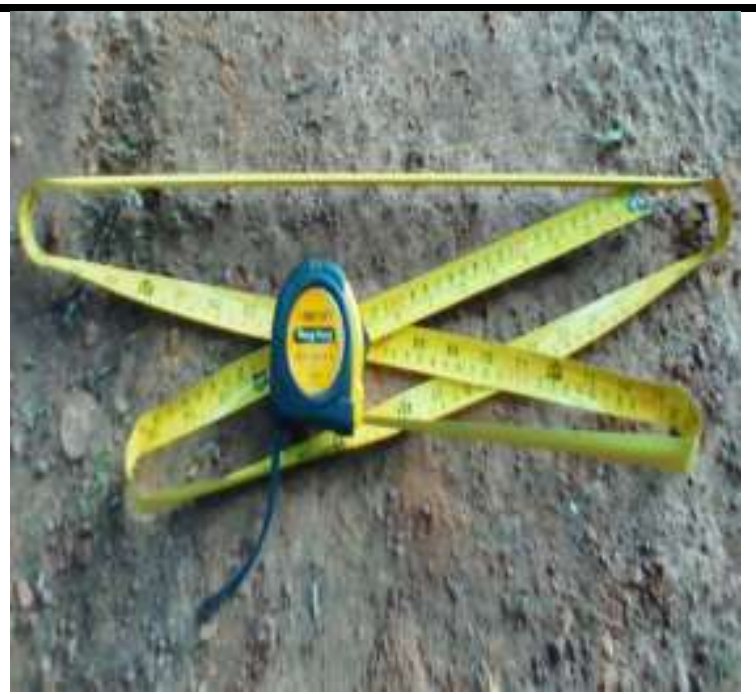

Fig. 6: Measuring Tape.

$\mathbf{S}=\frac{\mathbf{v}}{\mathbf{h}} \quad-\quad-$

Where; $\mathrm{S}=$ slope length (expressed as a ratio); $\mathrm{V}=$ Vertical distance in topography (rise). S.I unit in meter $(\mathrm{m}) ; \mathrm{h}=$ Horizontal distance in topography (run). S.I unit in meter (m).

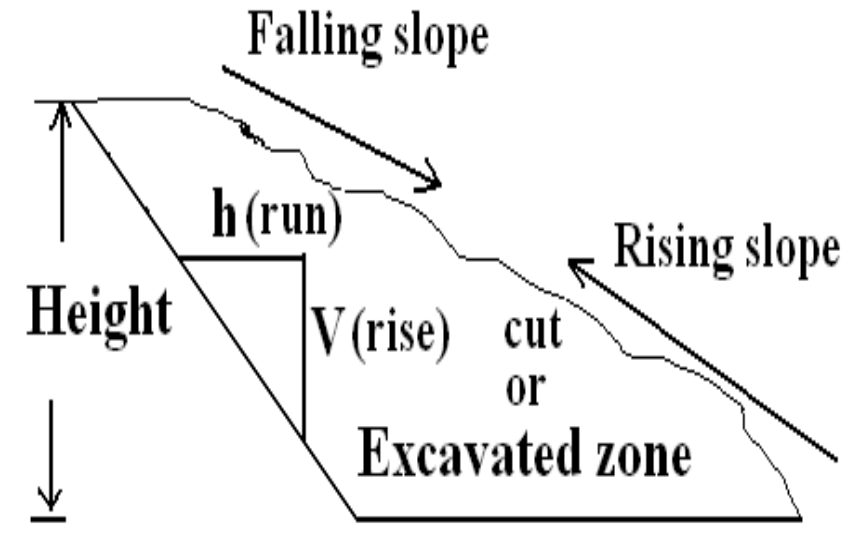

Fig.7: Run and Rise distances of a slope.

Slope Percent was determined was determined using the equation 2 ;

Slope percent, $S \%=\frac{V}{h} x \frac{100}{1}$

The Gradient was determined using equation 3;

Gradient, $\alpha=\arctan S \quad-\quad \quad-\quad \quad-$

Soil Loss Factor was determined using equation 4;

$\boldsymbol{L S}$ factor $=\boldsymbol{S} \times \boldsymbol{\alpha}$. $\quad$ - $\quad$ - $\quad$--

Using the topomap method, LS factor of Enugu State of Nigeria was obtained from a topomap sheet of Enugu State as provided in figure 8 . A ruler was used to measure the scale bar of the map at the bottom left corner as $2 \mathrm{~cm}$ on the map which equals $5000 \mathrm{~m}(5 \mathrm{~km})$ in real world (this also 
means one may adjust the computer screen size by zooming in or out till the map scale line at the bottom left of the topomap is equal to $2 \mathrm{~cm}$ when measured with a ruler). Point A was chosen within the topomap, and a line was drawn to a run direction in horizontal distance to point $B$. The distance of both points in the topomap would be identified as shown in figure 8 .

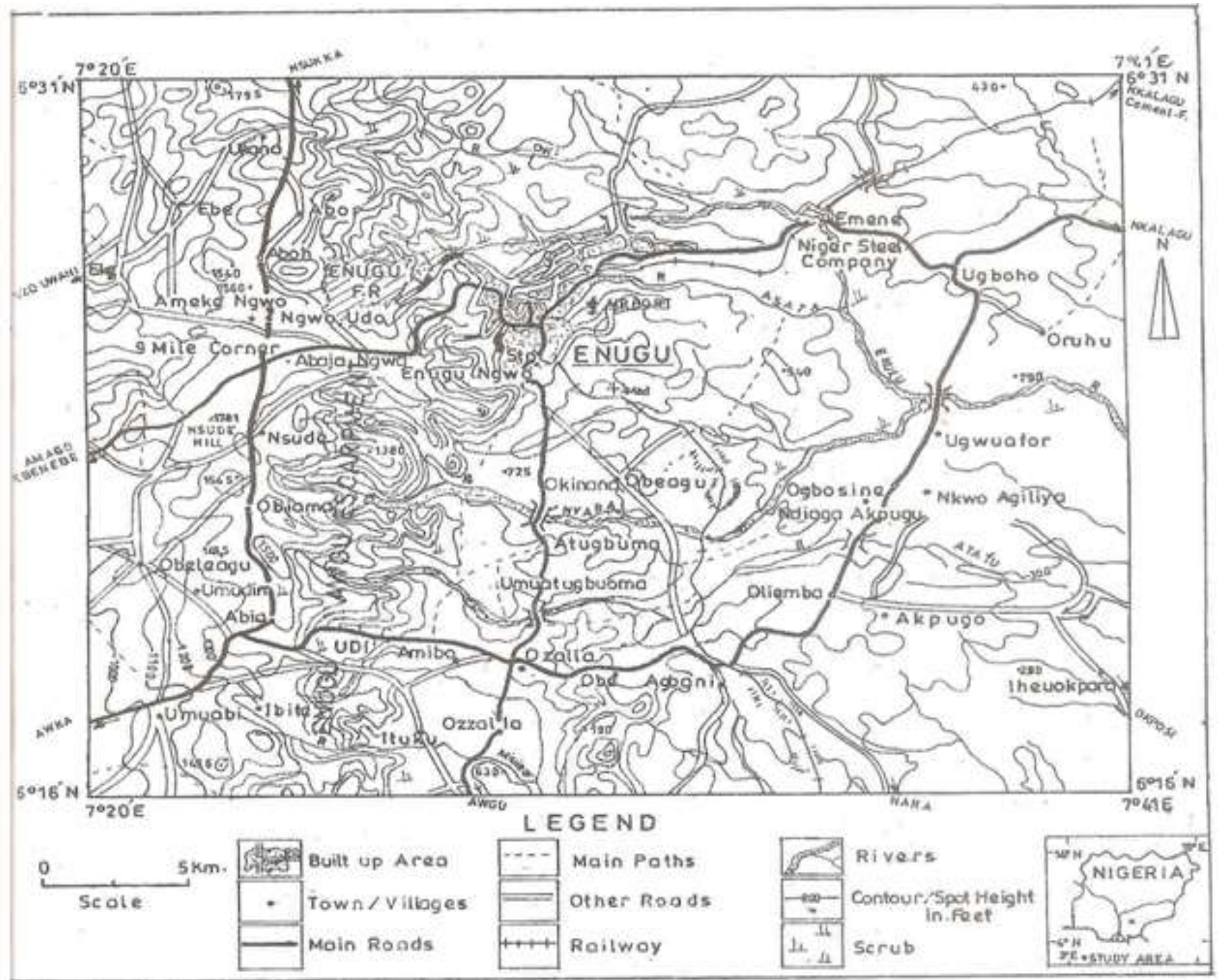

Fig.8: Topomap of Enugu (Scanned from the Ministry of Land and Survey, GRA, Enugu, Enugu State). 


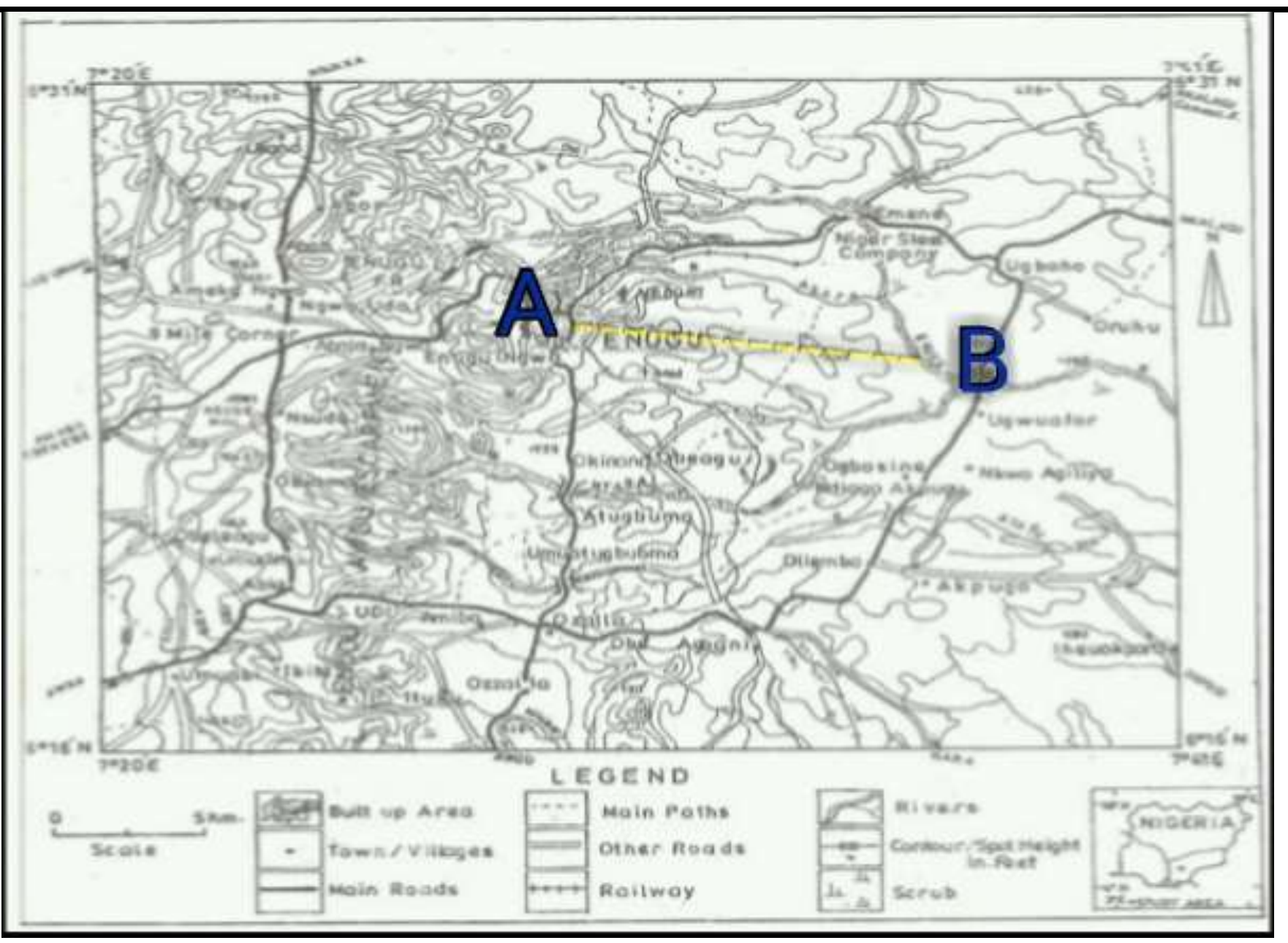

Fig.9: Topomap of Enugu State with point A and B (Edited from scanned copy from Ministry of Land and Survey, GRA, Enugu).

\section{RESULTS AND DISCUSSIONS}

Results are as tabulated below;

Table.1: Slope variables and LS factor for Enugu State and its capital city

\begin{tabular}{|c|c|c|c|c|c|c|}
\hline LOCATION & $\begin{array}{c}\text { RISE } \\
\text { (Vertical } \\
\text { Distance, } \mathrm{V}) \\
\mathrm{M}\end{array}$ & $\begin{array}{c}\text { RUN } \\
(\text { Horizontal } \\
\text { Distance, } \mathrm{h}) \\
\mathrm{m}\end{array}$ & $\begin{array}{c}\text { SLOPE } \\
\text { LENGTH, } \\
\mathrm{S}=\mathrm{V} / \mathrm{h}\end{array}$ & $\begin{array}{c}\text { SLOPE } \\
\text { PERCENT } \\
(\%)\end{array}$ & $\begin{array}{c}\text { SLOPE } \\
\text { ANGLE, } \\
\alpha=\tan ^{-1} \mathrm{~S}\end{array}$ & $\begin{array}{c}\text { LS FACTOR } \\
(\mathrm{S} \times \alpha)\end{array}$ \\
\hline ENUGU CITY & 5.55 & 26.50 & 0.2094 & 20.9434 & 11.8268 & 2.4765 \\
\hline ENUGU STATE & 1195 & 11500 & 0.1039 & 10.39 & 5.9317 & 0.6163 \\
\hline
\end{tabular}

The topographic factor otherwise known as the LS factor for Enugu State and its city gave; 0.6 and 2.5 respectively, this can be related to the value range in [14] universal soil loss equation;

$A=E=R x K x S L x C x P$ -

Where, $\quad \boldsymbol{A}=$ Annual soil loss (metric tons $\mathrm{x} \mathrm{m} / \mathrm{ha} / \mathrm{cm}$ of rainfall); $\boldsymbol{E}=$ Kinetic energy of rainfall (in metric tons $\mathrm{x}$ $\mathrm{m} / \mathrm{ha} / \mathrm{cm}$ of rainfall); $\boldsymbol{R}=$ Rainfall erosivity index (kinetic energy of rainfall, $\boldsymbol{E}$ x maximum intensity of rainfall in 30 minutes, $\left.\mathrm{I}_{30}\right) ; \boldsymbol{K}=$ soil erodibility $=0.7$ for fragile soil or
0.01 for stable soil (Depends on organic matter and texture of the soil, permeability and profile structure; $\boldsymbol{S} \boldsymbol{L}=$ Topographic factor $=0.1$ to 5 in most frequent farming contexts in West Africa and may reach 20 in mountainous areas depending on both length and gradient of slope; $\boldsymbol{C}=$ Plant cover factor $=0.001$ to 1 for forest region, 0.01 to 1 for grass lands and cover plants, 0.9 to 1 for root and tuber crops; $\boldsymbol{P}=$ Specific erosion practices $=$ From1 (for soil with no erosion control) to 0.1 (for soil with tied ridging on a gentle slope). 

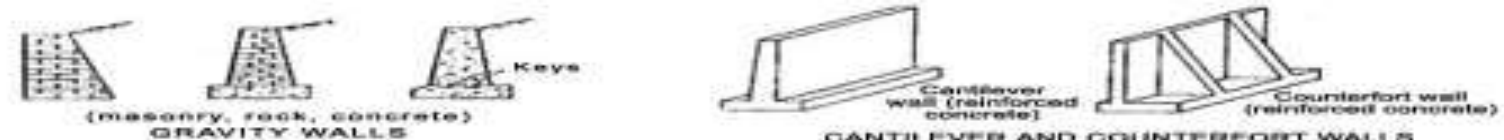

CANTILEVEF AND OOUNTERFORT WALLS
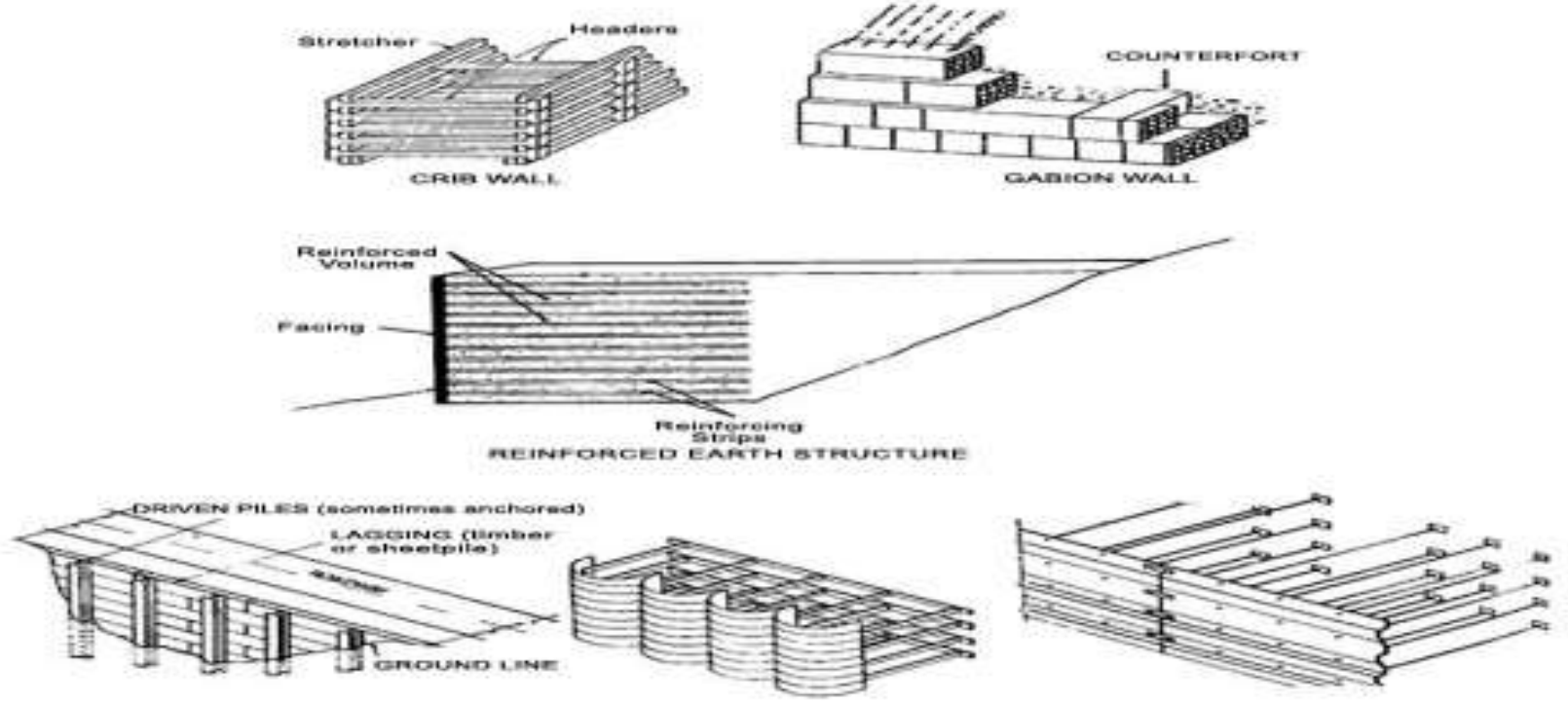

Fig. 10: USDA, Forest Service Technical guide, erosion prevention and control on timber sales areas, intermountain region

Also, from the erosion equation 5, erosion is the multiplication of its factors. Thus, if one factor of erosion is minimize to zero, erosion becomes equal to zero thereby not occurring at all. To manage slope and erosion cases related to it requires applications of some techniques like vegetation, reinforcement, etc. Vegetation provides cover to slope surfaces against erosion forces like rain drop splash. The root systems of live plants act in several ways to increase slope stability and serve as a binder for individual soil particles. Also, retaining structures maybe use to minimize erosion prior slope. In a case of a fall line, slope demands a more careful examination before calculating. A fall line (or fall zone) is the geomorphologic break between an upland region of relatively hard crystalline basement rock and a coastal plain of softer sedimentary rock. It is typically prominent when crossed by a river or other flowing water bodies, for there will often be rapids or waterfalls which creates room for erosion within the contact area of coastal plain (flatlands with relatively low relief) and Piedmont (region of foothills of mountain range) with high elevation.

\section{CONCLUSSION}

This work indeed provides practical solutions to $\boldsymbol{L F}$ factor using the two techniques as well provide means of minimizing erosion using slope. The $\boldsymbol{L S}$ factor for Enugu State and its capital city are 0.6 and 2.5 respectively.

\section{RECOMMENDATION}

More effort should be put in controlling the effects of slope and other erosion factors as they are the keys to preventing water erosion.

\section{REFERENCES}

[1] Atlas, 2016. Nigeria. World Map. Africa. Nigeria. World Atlas. p 1.

[2] FAO, 2016. Watershed management field manual. Forest department, Food and Agricultural Organization. Español Français. No.5; p29

[3] FAO, 1985. Irrigation water management : Introduction to irrigation. Training manual. Chapter 3. No. $1 ; \mathrm{p} 1$.

[4] Griffin, M.L., Beasley, D.B., Fletcher, J.J and Foster, G.R., 1988. Estimating soil loss equation on topographical non - uniform field and farm units. Journal of soil and water conservation. p326.

[5] Haan, C.T., Hatfield, B.J., Hayes, J.C., 1994. Design Hydrology and sedimentology for small catchments. Academic press, San Diego, CA, USA p 588.

[6] Hickey, R., 2000. Slope Angle and slope length solutions for GIS. Cartography. V. 29. No. 1. p 2 \& 4.

[7] NASA, 2007. NASA world wind. Satellite map of Enugu, Nigeria. NASA's globe software world wind. Blue Marble, MODIS, Land sat, SRTM,USGS or GLOBE. $p 3$. 
[8] Renard, K., Foster, G.R., Weesies, G.A., Porter, J.P., 1991. RUSLE: Revised universal soil loss equation. Journal of soil and water conservation, $\mathrm{p} 33$.

[9] Troeh, F.R, Hobbs, J.A and Donahue, R.L., 1991. "Chapter six: predicting soil loss". Soil and water conservation, 2nd Ed. Prentice-Hall, Englewood cliffs, New Jersey, U.S.A. p 21.

[10] USDA, Forest Service., 1989. Technical guide, erosion prevention and control on timber sales areas, intermountain region. $\mathrm{p} 17$.

[11] Watson, Thomas Leonard, 2010. Granites of the Southeastern Atlantic States, Bulletin 426, United States Geological Survey, Government Printing Office, Washington. (USGS.gov. Retrieved 2010-0812)."The Fall Line". A Tapestry of Time and Terrain. p 8.

[12] Wikipedia, 2013. Enugu State, zones.svg.png,maps. En.Wikipedia. p 27.

[13] Wikipedia, 2014. Enugu. Article on Enugu. en.m.wikipedia. $\mathrm{p} 8$.

[14] Wischmeier, W.H., and Smith, D.D., 1998. Predicting rainfall erosion losses. A guide to conservation planning. Agricultural Handbook, Sci. and Educ. Admin., U.S. Dept. Agr., Washington, D.C.537 